\title{
Should Both UNOS and CMS Provide Regulatory Oversight in Kidney Transplantation?
}

\author{
Bing $\mathrm{Ho}^{1}$ • Anton I. Skaro ${ }^{1}$ Michael M. Abecassis ${ }^{1,2}$
}

Published online: 19 April 2015

(C) Springer International Publishing AG 2015

\begin{abstract}
Since publication of the Centers for Medicare and Medicaid Services (CMS) Conditions of Participation Final Rule in 2007, there has been dual regulation of transplant centers by the Organ Procurement and Transplantation Network (OPTN) contractor the United Network for Organ Sharing (UNOS) and CMS. Herein, we summarize the environment leading to the development of the present regulatory framework and identify significant and unintended consequences of the current regulations.
\end{abstract}

Keywords Regulation · Program specific reports .

Transplantation $\cdot$ UNOS $\cdot$ Medicare

\section{Introduction}

The main objective of this manuscript is to examine the history and involvement of the Organ Procurement and Transplantation Network (OPTN)/United Network for Organ Sharing (UNOS) and the Centers for Medicare and Medicaid Services (CMS) within solid organ transplantation after implementation of the National Organ Transplant Act (NOTA).

This article is part of the Topical Collection on Kidney Transplantation

Michael M. Abecassis

mabecass@nm.org

1 Comprehensive Transplant Center, Northwestern University Feinberg School of Medicine, 676 North St. Clair Street Suite 1900, Chicago, IL 60611-2923, USA

2 Departments of Surgery and Microbiology-Immunology, Division of Organ Transplantation, Northwestern University Feinberg School of Medicine, 676 North St. Clair Street Suite 1900, Chicago, IL 606112923, USA
Our proposition is that OPTN/UNOS and CMS should work together in a complementary fashion and not separately. There should be minimal duplication of effort and improved alignment between these entities towards the overarching goal of effective, efficient, and judicious oversight of the field of transplantation.

\section{National Organ Transplant Act}

To address the nation's critical organ donation shortage and improve the organ matching and placement process, the National Organ Transplant Act (NOTA) was passed in 1984 and amended in 1988 and 1990 [1]. NOTA was sponsored by Representative $\mathrm{Al}$ Gore and Senator Orrin Hatch and signed into law by President Ronald Reagan. In brief, NOTA created a task force to study medical, legal, ethical, economic, and social issues presented by human organ procurement and transplantation. This included issues related to immunosuppressive medications, education, training, barriers, and insurance reimbursement. NOTA also outlawed the sale of organs in response to private enterprises such as the International Kidney Exchange, founded by Virginia physician H. Barry Jacobs [2]. Revised in 1998, NOTA's Title II-Organ procurement activities directed the Secretary of Health and Human Services (HHS), Donna Shalala at the time, to establish Organ Procurement Organizations for deceased donor transplants, the membership organization Organ Procurement and Transplantation Network (OPTN) and a data repository eventually known as the Scientific Registry of Transplant Recipients (SRTR). Both the OPTN and SRTR are required by law to be under contract by a private nonprofit entity. NOTA was further amended in 1990 to create the National Bone Marrow Donor Registry as well as minor amendments to existing procurement and transplantation authorities. More recently, 
legislation was introduced which dealt with kidney paired donation ensuring that this practice was not considered valuable consideration. Figure 1 depicts a current organization chart of CMS, Health Resources and Services Administration (HRSA), OPTN, and SRTR as well as reporting requirements.

\section{Overview of OPTN}

The OPTN contract has been held continuously by the Virginia-based UNOS since 1986. The OPTN Final Rule was initially published in 1998 but underwent more than 2 years of public comment and was delayed twice due to revision. Effective March 2000, HHS implemented the Final Rule establishing the regulatory framework for the OPTN and SRTR $[3,4]$. Despite the lengthy public comment period, the State of Wisconsin, University of Wisconsin Hospitals and Clinics Authority, Froedtert Memorial Lutheran Hospital, Oregon Health Sciences University, and the State of New Jersey brought a suit in federal court seeking injunctive relief from the Final Rule, which was dismissed November 2000. The Final Rule provides a framework for the operations of both the OPTN and SRTR.

Final Rule $\S 121.10$ stipulates that the OPTN "shall conduct special reviews of OPOs [Organ Procurement Organizations] and transplant programs, where the Secretary has reason to believe that such entities may not be in compliance with these rules or OPTN policies or may be acting in a manner which poses a risk to the health of patients or to public safety. The OPTN shall conduct these reviews in accordance with such schedules as the Secretary specifies..." [3] The Final Rule $\S 121.10$ further stipulates that "[OPTN] Board of Directors shall advise the Secretary of the results of any reviews and evaluations... which, in the opinion of the Board, indicate noncompliance with these rules or OPTN policies, or indicate a risk to the health of patients or to the public safety, and shall provide any recommendations for appropriate action by the Secretary. Appropriate action may include removal of transplant designation; termination of a transplant hospital's participation in Medicare or Medicaid; termination of a transplant hospital's reimbursement under Medicare and Medicaid; termination of an OPO's reimbursement under Medicare and Medicaid; if the noncompliance is with a policy designated by the Secretary as covered by section 1138 of the Social Security Act, or such other compliance or enforcement..." [3]

The OPTN Final Rule also indicates a minimum standard of designated transplantation program requirements and leaves wide latitude for OPTN to conduct reviews of OPOs and transplant programs, without any defined process, quality, or outcomes measures.

The OPTN adopted three well-defined criteria for quality assurance using the SRTR Program Specific Reports (PSR)

Fig. 1 Federal organization chart for organ transplantation. *Private, non-for-profit entity under federal contract. (With permission from UNOS)

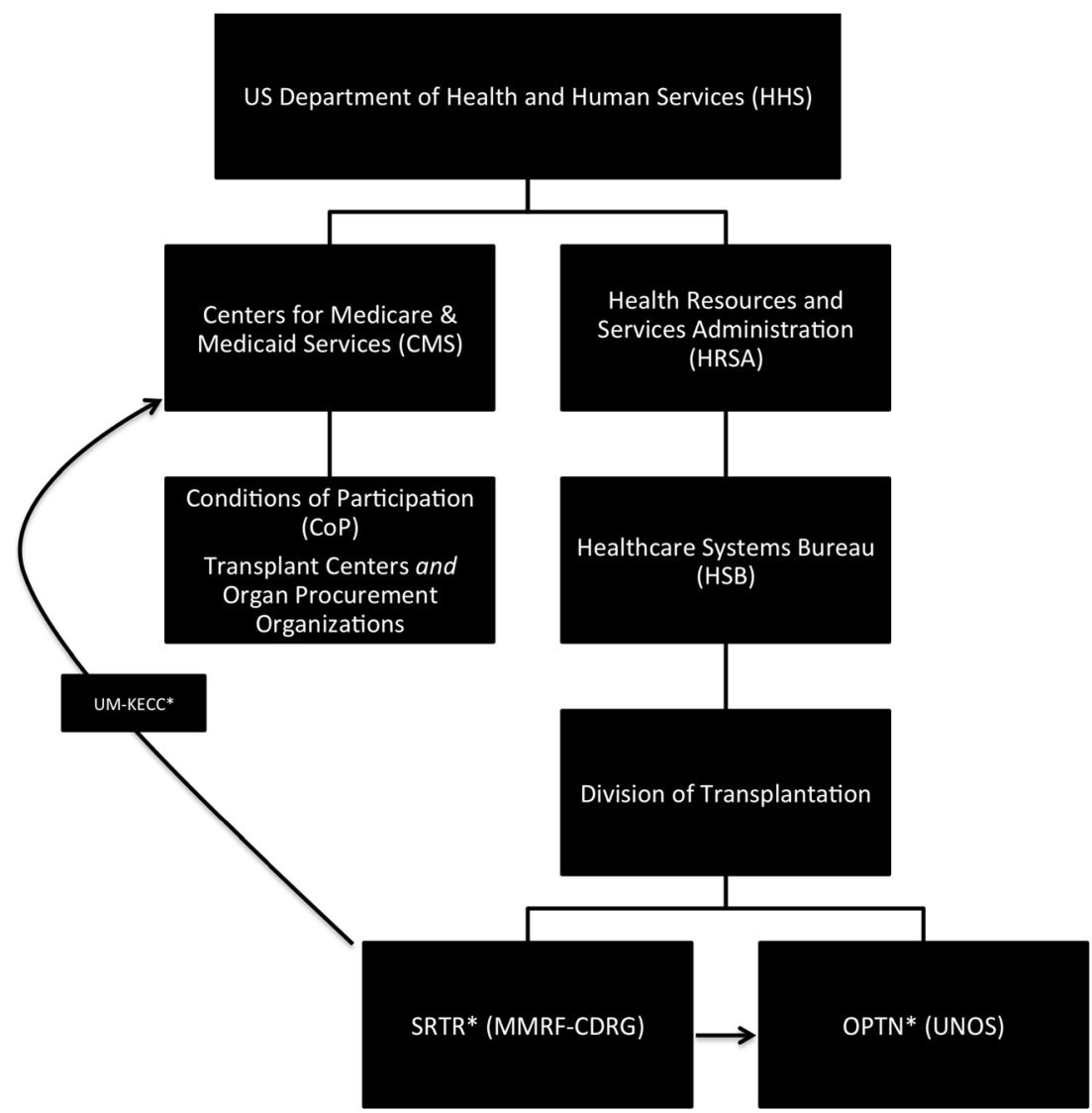


(Table 1) [5]. These criteria are intended to identify programs that need closer scrutiny. This scrutiny is intended to improve outcomes of underperforming programs [5].

The following contains excerpts with permission from UNOS:

"Oversight is accomplished through the UNOS Evaluation and Quality Department, and through the OPTN/UNOS Membership and Professional Standards Committee (MPSC), comprised of medical professionals from the field of transplantation who volunteer their time to ensure the integrity of the nation's transplant system. Strict monitoring and appropriate action to bring members back into compliance foster a high level of trust among transplant professionals" [6]. In 2015, UNOS will change the name of MPSC to the Department of Member Quality.

As described on the UNOS website [6], the OPTN is among the most comprehensive health care oversight programs in the country. Every organ allocation decision and algorithm is subject to monitoring based on input from the transplant community and data analysis.

- "UNOS" Department of Evaluation and Quality employs more than 40 staff members to ensure policies are followed. They examine patients' listing status and organ placement offers from deceased donors.

- UNOS routinely conducts on-site audits of patient records of all deceased donor transplant programs at least once every 3 years to verify that they follow OPTN bylaws and policies and the requirements of the OPTN Final Rule [3]. If a situation is discovered that poses an imminent threat to patient safety or public health, an on-site review is scheduled immediately.

- In order to protect all patients and the integrity of the transplant system, the OPTN/UNOS MPSC utilizes a confidential, peer review process designed to correct deviations as quickly as possible.

- Compliance with organ allocation policy exceeds $95 \%$. In the rare number of incidents where potential issues of noncompliance are identified, an even smaller percentage merits action by the committee following a thorough review of the circumstances.

Table 1 Criteria used by OPTN MPSC and CMS to identify programs that need further scrutiny

\begin{tabular}{lll}
\hline & OPTN & CMS \\
\hline Observed-expected & $>3$ & $>3$ \\
Observed/expected & $>1.5$ & $>1.5$ \\
$p$ value & Two-sided $p<0.05$ & One-sided $p<0.05$ \\
\hline
\end{tabular}

Large centers $\geq 10$ transplants in a 2.5 -year PSR cohort. Small centers $<10$ transplants in a 2.5-year PSR cohort. At least one event in cohort and a new event in subsequent cycle
"Although the main goal of the process is to protect patients by bringing members into compliance, MPSC actions may include as follows:

- Requiring corrective action plans and member selfassessments

- Issuing warning letters

- Issuing letters of reprimand

- Recommending that the board of directors place the member on Probation or declare the member "Not in Good Standing"

Based on MPSC findings, members may take additional process improvement actions. Changes that have "occurred as a result of MPSC action include the following:

- Member institutions have conducted internal audits to verify improvements.

- Transplant programs have closed, either temporarily while corrections are made, or permanently.

- Transplant institutions have made personnel changes to provide additional expertise and increase patient access to transplant services.

Other potential implications of MPSC actions could include as follows:

- Loss of Medicare certificate for an entire hospital (not just its transplant center)

- Requirement to notify the state department of health and patients

- Loss of professional reputation/standing for either a transplant institution or senior transplant professionals"

OPTN is not empowered to enforce OPTN requirements, unless they are approved by the Secretary of HHS as federal regulations [7]. Despite this, the MPSC is able to independently issue a Notice of Uncontested Violation, Letter of Warning, or Letter of Reprimand [8 8 . Further action by the OPTN Board of Directors can lead to probation (necessitating a Corrective Action Plan) or Member Not in Good Standing. The OPTN Board will also notify the Secretary of HHS, which can further take action which include, but are not limited to, the following:

- Removal of one or more of the member's designated transplant programs.

- Termination of the member's reimbursement under Medicare or Medicaid.

- Termination of a transplant hospital's participation in Medicare or Medicaid.

There is a preliminary interview process, and formal hearing process also outlined in the OPTN Bylaws. 


\section{Overview of the SRTR}

The SRTR contract was held by UNOS from 1987 to 2000. In September 2000, the contract was awarded to the University Renal Research and Education Association, which became the Arbor Research Collaborative for Health in July 2006. In September 2010, the contract was then awarded to the Minneapolis Medical Research Foundation (MMRF), whose Chronic Disease Research Group (CDRG) executes the contract [9•].

The OPTN Final Rule stipulates that the SRTR provide statistics and analyses to the public regarding the performance of transplant programs at least twice per year. The SRTR also produces an Annual Data Report and a biennial report to Congress. The Final Rule also stipulates that OPTN and SRTR respond to reasonable requests from the public for data needed for research. Finally, OPTN and SRTR carry out analyses requested by OPTN committees and HRSA, in support of efforts to improve organ allocation policies in the USA, or when special analyses or inquiries are necessary [9•]. An excellent summary of SRTR activities and functions is provided directly by the SRTR in Leppke et al. [9•].

The SRTR receives monthly data updates from the OPTN, which is person matched to Social Security Administration Death Master File (SSADMF), CMS via Consolidated Renal Operations in a Web-enabled Network (CROWN). In an unfunded mandate OPTN data is submitted by transplant centers, OPOs, and histocompatibility laboratories via a web-based manual submission process in UNet, UNet is the secure Internet-based transplant information database created by UNOS for the nation's organ transplant centers and OPOs to register patients for transplants, match donated organs to transplant candidates, and manage the critical data of all patients.

Beyond OPO and Program Specific Reports (PSR), SRTR also provides data to CMS through its contractor University of Michigan Kidney Epidemiology and Cost Center (UMKECC). These data are used by CMS for regulatory oversight of transplant programs.

\section{CMS Conditions of Participation}

Regulations for transplant centers and OPOs are two of the 20 CMS-issued Conditions of Participation (CoPs) and closely related Conditions for Coverage (CfCs) for health care organization domains, typically hospital and health care facility settings.

As the largest single payer of end stage renal disease (ESRD) in the USA, under 42 CFR Part 405 Subpart U "Conditions for Coverage of Suppliers of ESRD Services," CMS became the de facto kidney transplant regulator [10]. The CMS ESRD program is a key driver of the important role played by CMS as a transplant services payor in the USA. Under this program, almost all individuals in the USA who develop ESRD, regardless of age, are entitled to Medicare benefits, including renal transplantation, at a transplant center approved by CMS to perform kidney transplants. This coverage expanded into extra-renal organs and incremental implementation of regulations, for patients that demonstrated permanent medical disability or having reached minimum age for Medicare benefits. Most commercial payors have adopted CMS regulations [11].

These incremental regulations were further complicated by oversight through the Office of the Inspector General (OIG) via intermediaries in every state. These piecemeal regulations were sufficiently complex such that interpretative guidelines are necessary to interpret these regulations.

From 2005 to 2006, Los Angeles Times reporter Charles Ornstein published a series of articles highlighting a number of deficiencies within solid organ transplant programs within California, eventually leading to a Congressional review spearheaded by Senator Charles Grassley [12-45]. These inquiries led CMS to propose the CoPs in 2005 and a final rule in 2007 [46, 47]. Again, a series of interpretive guidelines have been released by CMS to clarify and interpret the Final Rule. These have been revised or expanded in the years since the release of the Final Rule. Furthermore, the regulations were phased in over a 3-year period from 2007 to 2010.

Although the CoPs substantially overlaps regulatory oversight authority OPTN was given in the OPTN Final Rule previously published in 2000 , shortly after adoption of the transplant center CoPs, Thomas Hamilton, Director of the Survey and Certification Group of CMS, indicated that the OPTN's regulation was a failure [48], citing the significant issues uncovered by Orstein's investigative journalism and subsequent Congressional hearings.

The CMS CoP is extensive, covering notification to CMS of transplant program changes, data submission, outcomes review, initial approval, patient and living donor selection, organ recovery and receipt, patient and living donor management, quality assessment and performance improvement (QAPI), human resources, organ procurement, and patient and living donor rights [47]. The mandated QAPI process requirement is extensive, and transplant centers must take actions that result in performance improvements and track performance to ensure that improvements are sustained [47]. QAPI is considered integral to improving outcomes in transplant programs, but also carries a significant burden for each transplant center [49•].

There are some salient differences between OPTN MPSC and CMS CoPs oversight.

The OPTN does not have oversight to approve or reapprove centers for Medicare, and CMS does not have regulatory statutory authority to delegate oversight authority responsibilities to OPTN [47].

CMS CoPs require transplant centers to meet or exceed expected 1-year patient and graft survival outcomes, similar 
to but more stringent than the three criteria established by OPTN with the use of a one-side $p$ value of 0.05 rather than a two-sided $p$ value of 0.05 . However, both metrics equally depend upon the risk adjustment models generated by the SRTR.

Furthermore, substantial documentation of policies and procedures and medical record documentation is necessary and audited in CMS site reviews. Simply demonstrating procedures is not sufficient, but individual patient-level documentation must reflect the procedures and protocols are being followed.

Whereas the self-stated purpose of OPTN MPSC is to bring members into compliance, CMS CoPs regulations offer no remediation. The PSR criteria were designed and intended to determine trends in transplant center performance, but adoption of the CMS approach has transformed these into a "bright line" test of whether a transplant center should be allowed to perform transplants, an application for which the PSRs were never designed nor intended [11]. There are two levels of response by CMS when a transplant center does not meet outcomes standards. A "condition" level citation is grounds for termination of a center's certification, when two of the last five PSRs, including the most recent report, exceed CMS' more rigorous tolerance range which perhaps overstates the statistical discriminatory capacity of the methodology currently employed [50•].

A center may request consideration of mitigating factors (MF), or extenuating circumstances that may have a temporary effect of meeting the $\mathrm{CoPs}$, and $\mathrm{CMS}$ provides up to 210 days for the MF deliberation process to demonstrate program improvements [50•]. CMS also notes that "the MF process permits a transplant program to benefit from its internal quality improvement efforts, but only if such efforts are effective, and are put in place early enough to provide clear evidence of improvement in graft and patient outcomes prior to the effective date of a prospectively scheduled Medicare termination." [51] The 1-year lag in the 2.5-year cohort within each PSR affords each transplant center an opportunity to proactively address CMS certification concerns if there is a robust QAPI system in place, and MF applications have been successful [51]. However, any benefit conferred by this lag is abolished by the nature of the construction of the 2.5-year cohort which requires a prolonged period for "washout" of poor outcomes from the system. Consequently, if additional time is necessary to come into compliance, a legally binding Systems Improvement Agreement (SIA), with a focus of onsite multidisciplinary peer review over a 12 -month period, can be employed [50•].

Over the 1-year phase-in period, implementation of CMS CoPs undeniably improved 1-year patient and graft survival, with programs cited having significant improvement in outcome, at the expense of a significant decline in transplant volume [50•], begging the question as to whether centers have become more risk averse. This would have significant implications on patients who might otherwise benefit from transplantation. Such that patients in certain high-risk strata, particularly those with characteristics that are not captured by the risk adjustment methodology utilized by the SRTR, might increasingly have limited access to life-saving transplants as programs endeavor to remain in regulatory compliance.

\section{Unintended Consequences in the Current Regulatory Environment}

It is important to note that the data collection imposed upon transplant programs and organ procurement organizations represent a growing unfunded mandate. Dual regulation imposes significant overhead to transplant centers and OPOs, and duplication of regulatory effort also introduces further inefficiency in the use of already scarce federal funds. The robust QAPI process mandated by the CMS CoPs most likely contributes to improved 1-year transplant outcomes since CoP implementation, at the cost of hundreds of thousands of dollars annually, without added funding or reimbursement [11]. What is less clear is if the proposed QAPI process is optimal or cost effective and whether center resources can be dedicated to centeror region-specific quality issues that more meaningfully contribute to improved outcomes. Furthermore, by focusing on the specific criteria of 1-year patient and graft survival, there is substantially less QAPI involvement in longer term outcomes and much less alternative outcomes such as quality of life. Arguably, it is not only the duration of life but the quality of that life that is of greatest interest particularly when patientcentered models of care are constructed. With the recent removal of 3-year risk adjustment and outcomes in the SRTR PSR, centers are left with even less information to monitor long-term trends in performance.

False flagging in the PSR has been demonstrated in simulation studies [52]. Using national data and simulating a range of poor-performing centers, both small- and large-volume centers may have false-positive flags, with large centers bearing a disproportionately higher burden. More ominously, in one of the simulation models, although flagged programs performed worse on average, they were not the worst-performing programs, and less than half of the worse-performing programs were actually flagged. Unfortunately, the CMS CoPs Final Rule $\$ 482.80$ and $\S 482.82$ do not account for the possibility of false flagging and centers are either deemed to meet requirements or not. Furthermore, MF do not provide for the possibility of false flagging, but require a clinically meritorious explanation for flagging on the outcomes requirements.

Significant limitations of the current risk adjustment methodology have been reviewed [11, 53, 54•]. One obvious clinical scenario is as follows. Despite the clearly increasing hazard ratio with increasing recipient age at transplant within the 
national OPTN data [55], there is a single adjustment at age $>55$, meaning that a recipient at age 56 has exactly the same predicted risk of 1-year graft failure or patient death as an 80year-old recipient of a living or deceased donor kidney. There is emerging understanding of the complicated relationship between donor and recipient age and outcomes [56-61] that a simple spline adjustment cannot adequately adjust for. There is ongoing development of cumulative sum control charts (CUSUM) and Bayesian hierarchical models by the SRTR that seek to address some of these issues. New risk adjustment models are scheduled for use beginning in 2015 that also address some of these issues. However, none of these approaches are likely to justify the current use of these metrics as a "bright line" test to be used to determine whether a kidney transplant program should remain CMS certified or be shut down.

Incentives for poor data quality are rampant within the current SRTR risk adjustment models. Missing data is currently corrected with multiple imputation methods, of which the net effect is to assign "average" risk to a covariate with missing data. This perversely incentivizes centers to only report covariates that maximize expected risk and under-report covariates where missing value imputation may be favorable. A recent consensus conference convened by the SRTR on transplant program quality and surveillance proposes the development of better quality indicators for data submission [5].

Risk aversion is increasingly observed in centers for highrisk scenarios where risk adjustment is not adequate, for example in ABO and cross-match-positive desensitization populations in kidney transplantation, liver transplantation for malignancies, and recipients with high cardiovascular disease morbidity. For centers "on the bubble," clinical and programmatic decision-making to preserve CMS certification rather than patient-centered care may dominate.

CMS CoPs are a potential threat to innovation, as there is no provision to waive inferior outcomes in the evaluation of new technologies and approaches. For example, data related to kidney paired donation is not presently accounted for in any current certification but serves to greatly expand patient access.

By reducing risk tolerance within transplant programs at risk for CMS decertification, there may be net effect of reduced access for moderate- and high-risk recipients. Given the universally increasing wait times and high annual mortality on the transplant wait list, many patient populations stand at risk for lack of access to transplantation. These effects are likely not geographically uniform and may take many years to ascertain the potentially chilling effect on access to transplantation.

Although the SRTR has previously rejected explicitly ranking transplant programs, there have been discussions about developing simplified one-size-fits-all five-star rankings for programs based on PSR performance. This substantially oversimplifies center performance and may accelerate risk aversion trends in transplant centers.

\section{Conclusions}

The environment and events leading to increased regulatory oversight of transplantation was based on suboptimal behavior and performance at a small number of transplant centers. The increased oversight has led to improved 1-year outcomes in patient and graft survival at significant cost, risk of false flagging, inadequate risk adjustment, no improvement in data quality and submission, and increasing risk aversion among centers, with a threat to innovation and reduced access to transplantation.

Although there are clear legal positions outlined by CMS justifying the development of transplant center $\mathrm{CoPs}$, they have resulted in significant duplication of effort (CMS and OPTN MPSC) which strains already scarce federal funds and introduces reduced efficiency within transplant centers as they struggle to react and remain in compliance with dual oversight. It is time to rethink the CoPs and OPTN MPSC to serve complementary functions rather than overlap regulations. An alignment towards the same objectives for OPTN and CMS would potentially allow more resources to be dedicated towards the mandate of "assuring equitable access by patients to organ transplantation and for assuring equitable allocation of donated organs among transplant centers and among patients medically qualified for an organ transplant.”[1]

\section{Compliance with Ethics Guidelines}

Conflict of Interest Bing Ho, Anton Skaro, and Michael M. Abecassis declare that they have no conflict of interest.

Human and Animal Rights and Informed Consent This article does not contain any studies with human or animal subjects performed by any of the authors.

\section{References}

Papers of particular interest, published recently, have been highlighted as:

- Of importance

1. National Organ Transplantation Act In: Congress US, editor. 1984.

2. Sullivan W. Buying of kidneys of poor attacked. New York Times. 1983 Sep 24; p. 9.

3. Organ procurement and transplantation network final rule. In: Services HaH, editor. 1998. p. 16296-336.

4. Stuart FP, Abecassis M. Organ allocation in the United States. In: Stuart FP, Abecassis MM, Kaufman DB, editors. Organ Transplantation. 2nd ed. Vademicum: Landes Bioscience; 2003. p. 66-73.

5. Kasiske BL, McBride MA, Cornell DL, Gaston RS, Henry ML, Irwin FD, et al. Report of a consensus conference on transplant program quality and surveillance. Am J Transplant : Off J Am 
Soc Transplant Am Soc Transplant Surg. 2012;12(8):1988-96. doi: 10.1111/j.1600-6143.2012.04130.x.

6. UNOS. Monitoring compliance with organ transplant policy in the United States. http://www.unos.org/donation/index.php?topic= fact sheet 8

7. McDiarmid SV, Pruett TL, Graham WK. The oversight of solid organ transplantation in the United States. Am J Transplant : Off J Am Soc Transplant Am Soc Transplant Surg. 2008;8(4):739-44. doi:10.1111/j.1600-6143.2007.02147.x.

8. OPTN Bylaws. http://optn.transplant.hrsa.gov/governance/bylaws/. 2014. Essentially reading regarding membership and due process within the OPTN.

9. Leppke S, Leighton T, Zaun D, Chen SC, Skeans M, Israni AK, et al. Scientific registry of transplant recipients: collecting, analyzing, and reporting data on transplantation in the United States. Transplant Rev. 2013;27(2):50-6. doi:10.1016/j.trre.2013.01.002. This is an excellent summary of the activities and function of the SRTR, written by the SRTR themselves.

10. Federal health insurance for the aged and disabled. In: Services $\mathrm{HaH}$, editor. Federal Registrar: Centers for Medicare and Medicaid; 1976.

11. Abecassis MM, Burke R, Cosimi AB, Matas AJ, Merion RM, Millman D, et al. Transplant center regulations - a mixed blessing? An ASTS Council viewpoint. Am J Transplant : Off J Am Soc Transplant Am Soc Transplant Surg. 2008;8(12):2496-502. doi: 10.1111/j.1600-6143.2008.02434.x.

12. Charles O, Alan Z. The state; Hospital halts liver transplant program; U.S. officials decertify the practice at UCI Medical Center. Waiting patients will transfer. Los Angeles Times. 2005 11/11/2005.

13. Charles O, Kimi Y. Transplant scandal puts CEO on Leave; UC Irvine's hospital chief is sidelined while the meltdown in its liver program is investigated. Organs were available while patients died. Los Angeles Times. 2005 11/17/2005.

14. Charles Ornstein AZ, Tracy W. Hospital's kidney transplant death rate raises concerns. Los Angeles Times. 2005 12/17/2005.

15. Ornstein C. Liver transplant program faulted. Los Angeles Times. 2005 12/28/2005.

16. Ornstein C. Embattled St. Vincent Hospital replaces CEO. Los Angeles Times. 2005 12/22/2005.

17. Ornstein C. Congressman expands probe into organ transplant centers. Los Angeles Times. 2005 12/01/2005.

18. Ornstein C. Hospital ends liver program; St. Vincent had skipped patients on a waiting list. Transplants of other organs will continue. Los Angeles Times. 2005 11/04/2005.

19. Ornstein C. Scrutiny of St. Vincent intensifies; a group may try to shut down the hospital's liver program after a patient low on a priority list got one. Also, a U.S. senator calls for an investigation. Los Angeles Times. 2005 10/20/2005.

20. Ornstein C. Hospital halts organ program; St. Vincent center in L.A. says a patient, 52nd on liver transplant list, got improper priority and the action was covered up. Los Angeles Times. 2005 09/27/2005.

21. Charles O, Christian B. UCI medical center on transplant probation; regulators impose the lesser penalty. In the hospital's liver scandal, 32 patients died waiting. Los Angeles Times. 2006 03/24/2006.

22. Charles O, Tracy W. Discipline meted out to Kaiser; transplant oversight group drops 'good standing' rating seven months after the HMO closes kidney program in San Francisco. Los Angeles Times. 2006 12/14/2006.

23. Charles O, Tracy W. St. Vincent closes its heart transplant unit; insurers stopped referring patients to the program after the hospital was sanctioned for its liver program. Los Angeles Times. 2006 11/ 17/2006.

24. Charles O, Tracy W. The state; times investigation; transplant monitor Lax in oversight; U.S. organ network routinely fails to detect problems; penalties often slight; patients, families can be left unaware of the risks. Los Angeles Times. 2006 10/22/2006.
25. Charles O, Tracy W. Hospital receives sanction; federal oversight group places San Diego's Sharp Memorial Hospital on probation for problems with its pancreas transplant program. Los Angeles Times. 2006 09/21/2006.

26. Charles $\mathrm{O}$, Tracy W. Kaiser to pay record fine over kidney program. Los Angeles Times. 2006 08/10/2006.

27. Charles O, Tracy W. Transplant report prompts inquiry; a U.S. senator asks two federal agencies why they haven't taken action against nearly 50 substandard centers around the country. Los Angeles Times. 2006 06/30/2006.

28. Charles O, Tracy W. U.S. Berates Kaiser over kidney effort; a withering report says the transplant program was poorly planned, staffed and run. The HMO does not admit or rebut the accusations. Los Angeles Times. 2006 06/24/2006.

29. Charles O, Tracy W. Transplant errors may cost Kaiser; HMO could lose federal funding for a whole class of kidney patients at its San Francisco hospital if it doesn't address U.S. inspectors' issues. Los Angeles Times. 2006 06/08/2006.

30. Charles O, Tracy W. U.S. begins kaiser probe; officials review kidney transplant program in which errors left many patients in limbo. Los Angeles Times. 2006 05/09/2006.

31. Charles O, Tracy W. Hospital is rebuked in organ case; L.A.'s St. Vincent, which bypassed patients waiting for livers, gets a rare public sanction from the national transplant network. Los Angeles Times. 2006 03/03/2006.

32. Ornstein C. Kaiser kidney services get U.S. Reprieve. Los Angeles Times. 2006 09/14/2006.

33. Ornstein C. State notifies deficient transplant programs; Medi-cal contacts four organ centers that need to improve. Serious problems could result in a loss of funding. Los Angeles Times. 2006 08/31/ 2006.

34. Ornstein C. Bill would allow fines for hospitals; transplant scandals propel a plan to give state regulators new power to penalize facilities for serious shortcomings in care. Los Angeles Times. 2006 08/ 26/2006.

35. Ornstein C. Tougher transplant oversight urged; lawmakers consider fines and other remedies to protect organ recipients and criticize regulators' lack of awareness. Los Angeles Times. 2006 08/16/ 2006.

36. Ornstein C. Deficient organ centers notified; federal regulators are contacting transplant programs that need to improve performance. Los Angeles Times. 2006 08/04/2006.

37. Ornstein C. Medicare's transplant monitoring defended; responding to a report on programs' failure to meet goals, an official says oversight is up. Los Angeles Times. 2006 07/04/2006.

38. Ornstein C. Troubled transplant center's plans OKd; a national oversight group approves L.A.'s St. Vincent's reforms, but sanctions remain. Los Angeles Times. 2006 06/30/2006.

39. Ornstein C. Medical center faces new woes; the U.S. is probing St. Vincent over its closed liver transplant program. The hospital is also losing money and laying off $8 \%$ of its staff. Los Angeles Times. 2006 04/27/2006.

40. Ornstein C. Report slams UCI's kidney transplant care. Los Angeles Times. 2006 02/16/2006.

41. Tracy W, Charles O. The nation; transplant centers penalized; the U.S. will pull funds from two subpar heart programs and says more such actions may follow. Los Angeles Times. 2006 11/29/2006.

42. Tracy W, Charles O. Four more transplant programs scrutinized; a national regulator finds problems at San Francisco, San Diego and two L.A. hospitals. Los Angeles Times. 2006 11/14/2006.

43. Tracy W, Charles O. The nation; no transplant data improvement; the number of federally funded programs that fail to meet U.S. survival standards doesn't budge. Los Angeles Times. 2006 07/ 29/2006

44. Tracy W, Charles O. A times investigation; feds ignore transplant site standards; medicare allows $20 \%$ of the 236 programs in the 
U.S. to stay in business despite performing too few operations or having low survival rates. Los Angeles Times. 2006 06/29/2006.

45. Ornstein C. U.S. transplant overseer sets guidelines; the agency focuses on organ donors who aren't officially brain-dead. Los Angeles Times. 2007 03/24/2007.

46. Hospital conditions of participation: requirements for approval and re-approval of transplant centers to perform organ transplants; proposed rule. In: Services HaH, editor. Federal Registrar: Centers for Medicare and Medicaid; 2005. p. 6140-82.

47. Medicare program; Hospital conditions of participation: requirements for approval and Re-approval of transplant centers to perform organ transplants; final rule. In: Services $\mathrm{HaH}$, editor. Federal Registrar: Centers for Medicare and Medicaid; 2007. p. 15198-280.

48. Hamilton TE. Improving organ transplantation in the United States - a regulatory perspective. Am J Transplant : Off J Am Soc Transplant Am Soc Transplant Surg. 2008;8(12):2503-5. doi:10. 1111/j.1600-6143.2008.02446.x.

49. Reich DJ. Quality assessment and performance improvement in transplantation: hype or hope? Curr Opin Organ Transplant. 2013;18(2):216-21. doi:10.1097/MOT.0b013e32835f3fcf. An excellent review of quality assessment and performance improvement regulation within tranpslantation.

50. Hamilton TE. Regulatory oversight in transplantation: are the patients really better off? Curr Opin Organ Transplant. 2013;18(2): 203-9. doi:10.1097/MOT.0b013e32835f3fb4. An excellent summary of the CMS' perspective on regulatory oversight since implementation in 2010, written by Thomas Hamilton, Director of Survey \& Certification Group in CMS.

51. Hamilton TE. Accountability in health care - transplant community offers leadership. Am J Transplant : Off J Am Soc Transplant Am Soc Transplant Surg. 2009;9(6):1287-93. doi:10.1111/j.16006143.2009.02683.x.

52. Massie AB, Segev DL. Rates of false flagging due to statistical artifact in CMS evaluations of transplant programs: results of a stochastic simulation. Am J Transplant : Off J Am Soc Transplant Am Soc Transplant Surg. 2013;13(8):2044-51. doi:10.1111/ajt.12325.
53. Abecassis MM, Burke R, Klintmalm GB, Matas AJ, Merion RM, Millman D, et al. American Society of Transplant Surgeons transplant center outcomes requirements - a threat to innovation. Am J Transplant : Off J Am Soc Transplant Am Soc Transplant Surg. 2009;9(6):1279-86. doi:10.1111/j.1600-6143.2009.02606.x.

54. VanWagner LB, Skaro AI. Program-specific reports: implications and impact on program behavior. Curr Opin Organ Transplant. 2013;18(2):210-5. doi:10.1097/MOT.0b013e32835f07f8. A critical review of the limitation of current SRTR programspecific reports.

55. Recipients SRoT. Risk-adjustment models. In: Services HaH, editor. 2014.

56. Hernandez RA, Malek SK, Milford EL, Finlayson SR, Tullius SG. The combined risk of donor quality and recipient age: higherquality kidneys may not always improve patient and graft survival. Transplantation. 2014;98(10):1069-76. doi:10.1097/tp. 0000000000000181.

57. Karim A, Farrugia D, Cheshire J, Mahboob S, Begaj I, Ray D, et al. Recipient age and risk for mortality after kidney transplantation in England. Transplantation. 2014;97(8):832-8. doi:10.1097/01.TP. 0000438026.03958.7b.

58. Dempster NJ, Ceresa CD, Aitken E, Kingsmore D. Outcomes following renal transplantation in older people: a retrospective cohort study. BMC Geriatr. 2013;13:79. doi:10.1186/1471-2318-13-79.

59. Fujiwara T, Tanaka S, Okada K, Namba K, Yamamoto H, Teruta S, et al. Impact of recipient aging on kidney allograft in living donor transplantation. Transplant Proc. 2014;46(2):454-6. doi:10.1016/j. transproceed.2013.10.059.

60. Hayes Jr D, Black SM, Tobias JD, Higgins RS, Whitson BA. Influence of donor and recipient age in lung transplantation. $\mathrm{J}$ Heart Lung Transplant : Off Publ Int Soc Heart Transplant. 2014. doi:10.1016/j.healun.2014.08.017.

61. Sharpton SR, Feng S, Hameed B, Yao F, Lai JC. Combined effects of recipient age and model for end-stage liver disease score on liver transplantation outcomes. Transplantation. 2014;98(5):557-62. doi:10.1097/tp.0000000000000090. 